\title{
ALGUNAS REFLEXIONES SOBRE LAS RELACIONES ENTRE LOS «DECRETOS DE CORTES CON CARÁCTER DE LEY»Y LOS «DEMÁS DECRETOS DE CORTES» DURANTE LA VIGENCIA DE LA CONSTITUCIÓN DE 1812
}

José F. ChOFRE SiRVENT Profesor Titular Interino de Derecho Constitucional

El concepto de ley propio y característico del Estado burgués encuentra su origen en la más vieja tradición europea, que arranca desde la Filosofía griega (Aristóteles), pasa por la Escolástica (Tomás de Aquino) y termina en la Edad Moderna (Gierke). Para esta corriente la ley no es la voluntad de uno, sino una norma general-racional; no «voluntas», sino «ratio» ${ }^{1}$.

Frente a este concepto de ley aparecen los defensores del absolutismo del Estado (Hobbes) y definen la ley como voluntad y mandato.

Precisamente, de la reacción contra este concepto absolutista de ley se depuró y afinó el concepto de ley propio del Estado burgués, como anteriormente hemos señalado. Y así, en esta misma línea de depuración técnica de dicho concepto, coincidieron los «monarcómanos» e Inglaterra, a pesar de la omnipotencia del Parlamento $^{2}$. En estos dos casos la ley, como categoría normativa, podría haberse constituído en vehículo «formal» que transportaría tanto normas generales-abstractas como normas individuales-concretas. La ley, por tanto, estaría capacitada para regular todo, cualquier tipo de materia. Sin embargo, en ambos casos no ha desaparecido la distinción entre ley como «ratio» y ley como «voluntas». Y así, por una parte, se encuentran las leyes (generales y abstractas), y, por otra, las «medidas» (mandatos individuales, bien dependa de la voluntad de uno - Rey absoluto-, o bien de la voluntad de muchos - acuerdo mayoritario del Parlamento ${ }^{3}$.

La distinción entre «leyes» y «otros actos que no son propiamente de legislación» hunde sus raíces en la tradición histórica española. No constituye, pues, una novedad radical que aparece con el constitucionalismo. Aunque es precisamente con éste donde alcanza mayores niveles de precisión jurídica.

\footnotetext{
${ }^{1}$ Vid. Schmitt, Carl, Teoría de la Constitución, Madrid, 1982, pág. 150.

${ }^{2}$ En relación con la «omnipotencia del Parlamento» en Inglaterra vid. García Pelayo, Manuel, Derecho Constitucional comparado, Madrid, 1959, pág. 310. Vid. Jennings, Sir Ivor, El sistema monárquico en Inglaterra, Madrid, 1966, págs. 31-48.

${ }^{3}$ Vid. Carl Schmitt distingue entre el concepto de ley propio del Estado de Derecho (norma general y abstracta) y concepto político de ley (medida concreta). Vid. op. cit., págs. 150 y 151 .
} 
De manera, que el tradicional concepto de ley propio de la burguesía, que arranca desde Aristóteles, y que define a la ley como norma general, permanente y abstracta, es el que se manifiesta en la obra de los constituyentes de Cádiz (véase, por ejemplo, el Discurso Preliminar a la Constitución de 1912). En ésta hay un claro espíritu de no confundir las leyes con «otros actos del Legislativo». Se excluye la posibilidad que la ley se configure como instrumento normativo que pueda englobar propiamente leyes y «otros actos de las Cortes». En la Constitución de Cádiz no todo lo que las Cortes producen son «decreto de Cortes con carácter de ley» ${ }^{4}$. Esta clara conciencia de los diputados gaditanos, que miraban de reojo la tradición histórica española, dio origen a los «decretos de Cortes con carácter de ley» y a los «decretos de Cortes sin carácter de ley».

La distinción entre ambas categorías normativas queda subrayada desde el momento en que se estableció un procedimiento de elaboración diferente para cada una de ellas.

Esta situación, caracterizada por sus nítidos perfiles, contrasta con la oscuridad en que se vieron inmersos, según C. Schmitt, los conceptos de ley y Estado de Derecho «a causa de haber aplicado, por razones y necesidades políticas, el procedimiento legislativo y la competencia de los órganos legislativos a otros actos del estado, como si fueran de legislación.» El procedimiento legislativo no convierte un acto que intrínsecamente no es ley en una ley. No puede admitirse, según C. Schmitt, «que todo lo que se toca con la varita mágica del procedimiento legislativo se convierta en una ley»5.

Así pues, el análisis de los conceptos de «decreto de Cortes con carácter de ley» $\mathrm{y}$ «decreto de Cortes sin carácter de ley» $\mathrm{u}$ otros actos del parlamento constituye uno de los aspectos fundamentales del constitucionalismo español durante todo el siglo XIX. Además, reúne unos caracteres originales que lo diferencian del resto del constitucionalismo occidental ${ }^{6}$.

Mientras que en el constitucionalismo europeo va desapareciendo paulatinamente la distinción entre leyes y otros actos del parlamento, y se va consolidando la denominación de «ley» para cualquiera que sea el acto producido por el poder legislativo, en España, en la Constitución de 1812, se consolida la existencia, fundamentalmente, de dos categorías normativas producidas por las Cortes - que nada tienen que ver con un concepto dualista de ley, porque por una parte hay «decretos de Cortes con carácter de ley» y, por otra, «decretos de Cortes sin carácter de ley», aunque en realidad son cuatro las categorías existentes de «decretos de

${ }^{4}$ Laband, en la segunda mitad del siglo XIX, consideraba que cualquier acto puede tener forma de ley. Para Carl Schimtt esta expresión insostenible en el concepto de ley propio del Estado de Derecho. Vid. de este autor op. cit., pág. 155.

${ }^{5}$ Vid. op. cit., pág. 154.

${ }^{6}$ Vid. Gallego Anabitarte, Alfredo, Ley y reglamento en el Derecho Público occidental,'Madrid, 1971, pág. 207. 
Cortes», atribuyéndose exclusivamente a uno de ellos el «carácter de ley» ${ }^{7}$. Ya en el «Reglamento para el régimen y gobierno del Estamento de Procuradores a Cortes», de 15 de Julio de 1834, no se distinguían las diferentes clases de «decretos», sino que únicamente se hacía referencia a los «proyectos de ley», dedicándoles el Título VII, que se denominó «Disposiciones peculiares a la discusión de los proyectos de ley». En iguales términos podemos referirnos al «Reglamento del Congreso de los Diputados», de 14 de Febrero de 1938, cuyo Título VII recibe la denominación «De los proyectos y proposiciones de ley». Y así, sucesivamente, con referencia a los Reglamentos de las Cortes habidos en los años posteriores. De tal manera, que la peculiaridad de que las Cortes elaboren diferentes categorías normativas es propio y exclusivo de la Constitución de 1812. Posteriormente, la ley adquirirá el protagonismo indiscutible que le corresponde. La ley se convertirá en el producto genuino de las Cortes.

La existencia de los dos Reglamentos de Cortes - 1813 y 1821 - durante el tiempo que ha permanecido en vigor la Constitución de 1812 va a contribuir a la delimitación de las dos etapas diferentes que afectaron de manera sustancial a la configuración definitiva de las dos categorías normativas objeto de estudio.

En la primera de las etapas se distinguen a su vez dos períodos distintos: uno de ellos comprende desde la entrada en vigor de la Constitución de 1812 y hasta el inicio del absolutismo, mayo de 1814; y el otro abarca desde la reinstauración del orden constitucional, en 1820, hasta la aprobación del segundo de los Reglamentos de Cortes, en 1821. Y la segunda de las etapas comienza con la entrada en vigor del Reglamento de las Cortes, de 1821, y alcanza hasta 1823, año que da principio la denominada «década ominosa».

\section{1) Etapa que abarca desde la entrada en vigor de la Cosntitución en 1812 hasta que concluya en 1821 la vigencia del Reglamento de Cortes de 1813.}

A) Periodo comprendido desde la entrada en vigor de la Constitución de 1812 hasta Mayo de 1814, inicio del absolutismo.

En el primer período de la primera etapa, aunque las Cortes ejercen poderes ilimitados y no permiten siquiera autorizar a la Regencia para que sancione las leyes ${ }^{8}$, ya se suscitó el problema de calificar si una determinada norma habría de

${ }^{7}$ Vid. Gallego Anabitarte, Alfredo, op. cit., págs. 204-206.

${ }^{8} \mathrm{El}$ artículo $113 \mathrm{del}$ «Reglamento para el gobierno interior de las Cortes», 4 de septiembre de 1813, establece lo que sigue: «En el caso que las Cortes no concedan a la Regencia, en los términos que les parezca, la sanción de las leyes, que pertenece por la Constitución al Rey, no podrán dejar de pedir antes de la votación de cualquiera proyecto de ley, informe a la Regencia, que lo dará, oyendo antes al Consejo de Estado.» 
revestir forma de «decreto de Cortes con carácter de ley» o de «decreto de Cortes sin carácter de ley». A quien correspondía definir dicha naturaleza era a las propias Cortes. Así, como ejemplos de lo que decimos, basta indicar dos casos: el primero es acerca de la derogación de los estatutos de la orden de Carlos III que exigían pruebas de nobleza para recibir esta condecoración los militares; pues bien, como cuestión previa a la discusión principal, el Sr. Marqués de Lazán presentó la siguiente proposición: «Que antes de pasar a discusión el dictamen de la comisión de Legislación sobre la derogación de los estatutos de la orden de Carlos III, se pregunte al Congreso si los considera como ley o no». Tras largo debate se declaró que eran leyes?.

Y el segundo de los supuestos que invocamos para demostrar que, en aquella primera época, ya se suscitaba el interés en definir qué era «decreto de Cortes con carácter de ley» 0 «decreto de Cortes sin carácter de ley» versaba sobre «la ejecución de un préstamo equivalente al valor de la contribución directa en un tercio, reintegrable en el primer año en que se hallare establecida»; después de una larga y detenida discusión, formuló el Sr. Caro la siguiente indicación, sobre la que se declaró no haber lugar a deliberar: «Que antes de votar sobre el informe de la Comisión de Hacienda, declaren las Cortes si la minuta de decreto que dicha Comisión presenta es o no de ley». (Lamentablemente, el debate en torno a los dos ejemplos citados no se recoge en las Actas de las Sesiones de las Cortes ${ }^{10}$.

Pero a pesar de suscitarse el interés por definir la naturaleza de unas concretas categorías normativas (lo cual revela el lento despertar - porque desde 1810 ya se conoce la existencia de las dos categorías normativas: por una parte, «decreto de Cortes con carácter de ley» y, por otra, los demás «decretos de Cortes»- de una conciencia jurídica que considera que los productos que emanen de las Cortes son de diferentes clases, y no, como sería de suponer, exclusivamente la «ley»), lo cierto es que durante el primer período de la primera etapa, que termina el 14 de Mayo de 1814 , sólo se aprobaron «decretos de Cortes sin carácter de ley», justificándose este hecho en que el Rey, al encontrarse cautivo, no puede ejercer el derecho a sancionar los «decretos de Cortes con carácter de ley» y, por tanto, las Cortes se arrogan poderes casi ilimitados.

B) Período comprendido desde la reinstauración del orden constitucional en 1820 hasta el 29 de Junio de 1821, en que se aprobó el segundo Reglamento de las Cortes.

En el segundo período de las primera etapa, sin embargo, el panorama va

${ }^{9}$ Vid. Actas de las Sesiones de la Legislatura ordinaria de 1813, Tomo único, no 66, pág. 321 .

${ }^{10}$ Vid. Actas de las Sesiones de la Legislatura ordinaria de 1813 , Tomo único, $\mathrm{n}^{\circ} 51,16$ de Noviembre de 1813, pág. 249. 
alcanzando paulatinamente niveles de complicación de alguna entidad a medida que el Rey comienza a ejercer las facultades que por la Constitución le corresponde. Además de esta importante circunstancia hay que señalar la novedad que supone para los diputados llevar a la concreción práctica las distintas categorías normativas, que si bien ya se contemplaban en el Reglamento de las Cortes, de 1913, no se llegaron a aplicar en caso alguno (durante los años 1812-1814 sólo se aprobaron «decretos de Cortes», a iniciativa de éstas y sin sanción real).

Esta novedosa situación creó desconcierto entre los parlamentarios, llegando a cuestionarse en repetidas ocasiones si la norma ante la cual se encontraban reunía los caracteres propios de un «decreto de Cortes con carácter de ley» o de un «decreto de Cortes sin carácter de ley». Hubo algún diputado, incluso, que, celoso defensor de la puridad de conceptos, consideraba que la Constitución de 1812 no contemplaba la distinción entre «ley»y «decreto de Cortes». Este diputado al que nos referimos era el Sr. Calatrava, que realizó estas manifestaciones con ocasión de la discusión del proyecto de ley sobre señoríos. Además, añadía que el Reglamento de las Cortes sólo hablaba de decretos, y no reconocía más diferencia entre éstos que la de necesitar unos sanción real y otros no ${ }^{11}$. A modo de aclaración téngase en cuenta que en el Reglamento de las Cortes, de 1813, así como el de 1821, no se contienen formalmente «leyes», sino que hay cuatro clases de decretos, siendo uno de ellos los «decretos de Cortes con carácter de ley». De ahí que haya que interpretar la intervención del diputado Sr. Calatrava en el sentido de si la categoría en cuestión es un «decreto de la exclusiva competencia de las Cortes», o es un «decreto de Cortes con carácter de ley». Para este parlamentario, la Constitución «no podía menos de repugnar la distinción ingeniosa que se había inventado entre decreto y ley» ${ }^{12}$.

Ejemplos que avalan lo que decimos se repiten continuamente. Así, cuando se

\footnotetext{
${ }^{11}$ Con ocasión de la discusión del proyecto de ley sobre señoríos se dijo lo siguiente: «Declarado el punto suficientemente discutido, en el momento de procederse a la votación se opuso el señor Calatrava a que se preguntase si el presente debía considerase como ley o como decreto; porque la Constitución no conoce semejante distinción, y porque este lenguaje le parecía inconstitucional, y que por lo mismo no debían usarlo las Cortes. Añadió que el Reglamento solo hablaba de decretos, y no reconocía más diferencia entre éstos que la de necesitar unos la sanción Real, y otros no necesitarla; y que los de esta clase eran los que se acordaban a propuesta del Rey, o por estar en las atribuciones de las Cortes; que de declararse por éstas que era decreto y no ley, se podría publicar sin la sanción Real, lo cual en su juicio sería contra la Constitución; que no podía menos de repugnar la distinción ingeniosa que se había inventado entre decreto y ley, distinción que autorizaría a las Cortes para atribuirse facultades que excederían sus límites, destruyéndose por este medio el equilibrio que establece la Constitución. Reprodújose en breves términos la anterior discusión, y para cortarla indicóel Sr. Vargas, y apoyó el señor Golfín, que lo que debía preguntarse era si la lectura hecha debía considerarse como primera o como tercera, y añadiendo éste que tenían mucha fuerza las reflexiones que acababa de hacer el Sr. Calatrava. Después de algunas contestaciones entre los sres. Castanedo y Cepero, el primero en orden a que no era anticonstitucional el decir «decretos de Cortes», pues así los habían titulado las Cortes extraordinarias, y el segundo sobre el sentido en que habían usado la palabra 'mandato', que había notado el Sr. Golfín; habiéndose preguntado si la lectura que se había hecho del dictamen de la comisión se tendría por primera o por tercera lectura.» Vid. Diario de Sesiones de las Cortes, Tomo II, núm. 38, 4 de Abril de 1821, pág. 880.

${ }^{12}$ Vid. Idem.
} 
leyó la minuta de decreto en relación con los jesuítas, el diputado Sr. Calatrava dijo: «Dudo si este decreto es de aquellos que necesitan la sanción del Rey» ${ }^{13}$. Otro caso que viene a demostrar la confusión existente en la utilización de las distintas categorías normativas lo encontramos con ocasión del dictamen de la Comisión de Guerra en el que se examina la consulta del Tribunal especial de Guerra y Marina, relativa a si el sumario que se está sustanciando en averiguación de los desórdenes ocurridos en el cuartel de Guardias de la persona del Rey debe formarse por uno de los ayudantes o por el juzgado del cuerpo ${ }^{14}$; pues bien, en este dictamen se menciona el «decreto de las Cortes generales y extraordinarias» de 25 de Mayo de 1813, y, sin embargo, en las intervenciones posteriores se utilizaron, indistintamente, los términos $\left\langle\right.$ ley ${ }^{15}$, o «decreto de Cortes ${ }^{16}$. Obviamente, por la fecha en que se aprobó, 1813 , ha de calificarse como «decreto de Cortes» y no como «ley», o también llamado «decreto de Cortes con carácter de ley», ya que, como sabemos, la ausencia del Rey impide a éste sancionar las leyes.

El clima de confusión existente en el seno de las Cortes acerca de qué deba entenderse por «decreto de Cortes con carácter de ley» no había conducido aún a una discusión específica sobre tan importante asunto. Por tanto, la imperiosa necesidada de determinar con la mayor precisión posible los rasgos característicos de cada una de las categorías normativas obligaba a las Cortes a discutir sobre dicha cuestión.

a) Importante debate en las Cortes acerca de la distinción entre «decretos de Cortes con carácter de ley» $y$ «los demás decretos de Cortes».

Pues bien, apenas transcurrieron cuatro meses desde la reinstauración del

\footnotetext{
${ }^{13 "}$ "Se leyó la minuta de decreto extendida a tenor de lo aprobado en la sesión de 14 del actual con respecto a los jesuítas; y leída, dijo

El Sr. Calatrava: Dudo si este decreto es de aquellos que necesitan la sanción del Rey. Hágalo presente porque advierto que está extendido con la fórmula adoptada para los decretos que según el Reglamento no necesitan la sanción Real; y me parece que esto debe llamar la atención del Congreso.

El Sr. Presidente: En la Secretaría se tuvo presente que en la Memoria del Secretario de Gracia y Justicia se decía que S. M. dejaba este punto a la resolución de las Cortes. Con este motivo, y el de no ser una nueva ley, sino la reproducción de las que regían desde el año de 1767, se acordó que se leyese para que el Congreso determinase lo que pareciese justo.

El Sr. Calatrava: Tres son las clases de fórmulas de decretos que están señaladas en el Reglamento. Primera: la de aquellos que son relativos a puntos que por la Constitución pertenece su resolución a las Cortes, tal como la declaración de dudas sobre la sucesión de la Corona, y otros semejantes. Segunda: la de aquellos que tienen su origen en las propuestas del Gobierno. Y tercera: la de aquellos en que no habiendo ninguna propuesta del Gobierno, acuerden, sin embargo, las Cortes lo conveniente. Si en el caso actual las Cortes se hubiesen conformado con lo que el Gobierno hubiese propuesto, no habría que dudar y se adoptaría la fórmula correspondiente; y así como si hubiese sido de aquellas cosas que las Cortes determinan por sí sin propuesta del Rey, se usaría de la fórmula señalada para este caso. Pero veo que aquí se usa de la de aquellos puntos cuya sanción está en las facultades de las Cortes, y yo creo que este negocio es de aquellos sobre que debe recaer la sanción Real; pues aunque es cierto que el Rey lo dejó a la resolución de las Cortes, se abstuvo de manifestar su opinión». Vid. Diario de Sesiones de las Cortes, Tomo I, núm 43, 16 de Agosto de 1820, pág. 535.

${ }^{14}$ Vid. Diario de Sesiones de las Cortes, Tomo I, núm 14, 18 de Julio de 1820, pág. 191.

${ }^{15} \mathrm{El}$ diputado Sr. Paralea utiliza la expresión «ley de 25 de Mayo de 1813». Vid. idem.

${ }^{16}$ En el dictamen de la comisión de Guerra se utiliza la expresión «decreto expedido por las Cortes
} 
régimen constitucional, se suscitó en el seno de las Cortes una de las cuestiones más importantes de que pudiere conocer el Poder Legislativo en aquella época, como es la de distinguir entre «decreto de Cortes con carácter de ley» $\mathrm{y}$ «decreto de Cortes sin carácter de ley» ${ }^{17}$.

Con motivo de la discusión del asunto de si ha de volver a entrar en la sucesión de la Corona el Sr. Infante Don Francisco de Paula y a S. M. Doña María Luisa, gran duquesa de Luca, el Presidente de las Cortes, Sr. Espiga, juzgó como muy necesario que se declarase de forma inmediata si nos encontramos ante un «decreto de Cortes con carácter de ley» 0 ante un «decreto de Cortes sin carácter de ley», porque según se resuelva esta cuestión previa la dirección de la discusión será muy diferente. Porque hay razones en favor de cada una de las posturas defendidas. Por una parte, al ser el objeto de entidad, y porque se dirige a la Nación entera parece que debe tener el «decreto de Cortes» carácter de ley; por otra parte, como no es general, y sólo tiene como objeto una persona, se considera que el «decreto de Cortes» no tiene carácter de ley ${ }^{18}$.

Llegados a este punto, el Secretario Sr. López planteó la discusión, con una claridad meridiana, en los siguientes términos: «Este negocio será objeto de un decreto o de una ley? $»^{19}$.

El debate que provocó la formulación de este interrogante dejó traslucir una cierta confusión de conceptos de no poca entidad, demostrándose con ello que las categorías normativas aun no han encontrado una definición adecuada que se corresponda con la relevancia que tienen para el desarrollo legislativo, al cual le corresponde la difícil tarea de conformar las bases del inicipiente Estado Constitucional.

a') Principales argumentos utilizados a favor o en contra del calificativo «decreto de Cortes con carácter de ley».

Los argumentos utilizados a favor o en contra de calificar con «carácter de ley» a los «decretos de Cortes» en la discusión de referencia pueden ser agrupados en torno a tres núcleos fundamentales.

generales y extraordinarias de 25 de Mayo de 1813» y en iguales términos se expresan los diputados Sres. Giraldo y Sánchez Salvador. Vid. idem.

${ }^{17}$ Vid. Diario de Sesiones de las Cortes, Tomo I, núm. 9, 13 de Julio de 1820, pág. 74.

18"El Sr. Presidente: En el día pasado se dudó si esta proposición debería considerarse como una ley o un decreto. Juzgo muy necesario que se declare esto antes, porque la dirección de la discusión será muy diferente. Hay razones de una y de otra parte. Por ser de tal entidad el objeto, y porque se dirige a la Nación entera, parece que tiene el carácter de ley; por otra parte, como no es general, y solo tiene por objeto una sola persona, parece debe tener la calidad de decreto. Las Cortes resolverán lo que tengan por conveniente; en inteligencia que la discusión, si se considera como ley, ha de seguir diferentes trámites que los que se seguirán si se considera como decreto.» Vid. idem.

${ }^{19}$ Vid. idem. 


\section{a") La ley es una disposición general y perpetua».}

Por una parte, se encuentran aquellos diputados defensores de la tesis que estima que el asunto de que se trata es una ley, y afirman que merece tal consideración porque nos encontramos ante una «disposición general y perpetua»; «general», porque obliga a toda la Nación; y «perpetua», porque carece de tiempo determinado para su cesación ${ }^{20}$. Este argumento está huérfano de sólidos fundamentos, porque igual que los «decretos de Cortes con carácter de ley», también los «decretos de Cortes sin carácter de ley» pueden tener la misma fuerza para obligar a toda la Nación; y en cuanto al carácter de la «perpetuidad» tampoco está limitada la vigencia de los decretos a un plazo concreto. Luego las características de «generalidad» y «perpetuidad» no son exclusivas de los «decretos de Cortes con carácter de ley» como se pretende demostrar ${ }^{21}$.

\section{b') La ley, como expresión de la voluntad del pueblo por sí o por sus} representantes.

En segundo lugar, se argumenta por los defensores de calificar la normativa como «decreto de Cortes con carácter de ley», que tiene dicha consideración porque ostenta el atributo esencial de ella, que es ser «la expresión de la voluntad del pueblo manifestada por sío por sus representantes $»^{22}$. Esta afirmación carece de la rotundidad que parecen querer atribuirle los defensores de la calificación como «decreto de

20"El Sr. Moreno Guerra: Creo que es muy claro que esto debe seguir los trámites de una ley, porque se trata de una disposición general y perpetua. Es general, porque obliga a toda la Nación; y es perpetua, porque no puede ser revocada sino haciendo una ley. Lo que se llama perpetuo es lo que ha de subsistir hasta que se revoque expresamente; quiero decir que no hay tiempo determinado para su cesación.»Vid. idem.

21"E1 Sr. Montoya: La diferencia que debe hacerse entre las leyes y los decretos de las Cortes no debe tomarse de su perpetuidad ni de lo general de su objeto, pues tanto las leyes como los decretos pueden tener este carácter. Se distinguen solamente en que las leyes requieren la sanción Real, y en los decretos la sanción reside exclusivamernte en las Cortes, por atribuirlas la Constitución la determinación de semejantes asuntos, cual es ciertamente el excluir alguna persona de la sucesión del Trono.» Vid. Diario de Sesiones de las Cortes, Tomo I, núm 9, 13 de Julio de 1829, pág. 75.

${ }_{22 "}$ El Sr. Navarro (D. Andrés): Me parece que la declaración de que se trata es una verdadera ley, porque reúne todos sus caracteres. En primer lugar, es ley porque tiene el atributo esencial de ella, que es ser la expresión de la voluntad del pueblo manifestada por sí o por sus representantes. ¿De qué se trata aquí? De que la Nación por medio de sus representantes manifieste su voluntad; pues manifestándola, se trata de hacer una verdadera ley. Se podrá decir que no basta esta manifestación, sino que se necesita además la importancia del objeto. ¿Y no reúne ésta la importancia del objeto? ¿No se trata del llamamiento a la Corona? ¿Y no es este el objeto más importante de la legislación? Reúne, pues, también el atributo de la importancia del objeto. Si se pide que esta manifestación de la voluntad general se dirija al bien de la nación, el establecimiento de las leyes del llamamiento a la sucesión de la Corona, ¿ $i$ qué se dirige sino al bien de la Nación? Ahora, si se objeta que la ley debe referirse a la comunidad, no a los intereses de los particulares, tiene también este carácter la de que se trata. Aunque en una ley se trata de un objeto particular, no por esto deja de ser, siempre que incluye una obligación a la que quede sujeta la generalidad. En estando sujetos a ellas todos los súbditos, se verifica el carácter de la ley. Si se exigiese precisamente que una ley hubiese de mirar directa a inmediatamente al bien particular de todos, nos hallaríamos en el caso de tener que excluir de la clase de leyes a las más principales de ellas. Todas las leyes que tratan de la sucesión a la Corona, atienden al interés particular de una familia y de sus individuos: ¿y las debemos privar del carácter de leyes por esto? Concluyo, pues, que esta proposición tiene todos los caracteres de 
Cortes con carácter de ley», porque el pueblo también expresa su voluntad a través de sus representantes de forma distinta a este tipo «decretos de Cortes con carácter de ley», por ejemplo, a través de los «decretos de Cortes sin carácter de ley»; independientemente del caso que nos atañe, cuando las Cortes dictan «decretos de Cortes sin carácter de ley» también en este caso es expresión de la voluntad general, y más auténtica incluso porque dimana directa y únicamente de la soberanía nacional. En el mismo sentido se pronuncia Martínez de la Rosa que, con gran agudeza, mostró su desacuerdo, con ocasión de otro debate, en estos términos: «No es exacto que la ley sea la expresión de la voluntad general; y aunque así lo han dicho autores célebres, no lo tengo por un principio infalible. Si toda expresión de la voluntad general fuera ley, todo lo que las Cortes mandasen sería ley; es así que no lo es, luego es clara la consecuencia» ${ }^{23}$.

c') Ley, por razón de la materia.

Y, por último, el diputado Sr. Gareli considera que la materia de que se trata es propia de un «decreto de Cortes con carácter de ley», y para sostener esta afirmación apoya, fundamentalmente, su argumento en que como el art. 181 de la Constitución de 1812 concede a las Cortes la facultad de excluir de la sucesión a aquellas personas que considere capaces para suceder, y las Cortes dieron su decreto de exclusión antes de promulgarse la Constitución, para que las cosas vuelvan a su orden debe haber otro decreto que restituya a él, y este decreto ha de tener carácter de ley, porque restablece el orden señalado en la Constitución ${ }^{24}$.

Pero, ¿por qué ha de revestir el decreto en cuestión carácter de ley, si el primero de los decretos de exclusión fue dado sólo por las Cortes, sin necesidad de sanción por S. M.? Para la restitución de aquel decreto bastaría seguir las mismas formalidades a las que se ajustó la aprobación del decreto primero. Pero frente al diputado Sr. Gareli y otros, como los diputados Sres. Moreno Guerra y Sr. Navarro, que defendía la tesis de que la categoría normativa de que se trata es un «decreto de Cortes

\footnotetext{
ley, y de ley propia y verdaderamente tal; y no sólo de ley, sino ley fundamental, y de aquellas que pertenecen a la sucesión a la Corona; y así, para su aprobación deben seguirse los trámites no sólo de una ley, sino de una ley fundamental.» Vid. idem.

${ }^{23}$ Vid. Diario de Sesiones de las Cortes, Tomo I, núm 57, 29 de Julio de 1820, pág. 725.

24"El Sr. Gareli: Me parece que este es un decreto, pero de aquellos que tienen el carácter de ley, de los que habla el artículo 108, Capítulo X del Reglamento, y que por lo mismo deben tener la sanción Real. En el fondo esta es una ley, porque trata de la sucesión a la Corona, que es una de las cosas de que habla la ley fundamental. En ella se designa la clase de personas llamadas a la sucesión de la Corona, y en éstas están incluídas las personas del Señor Infante D. Francisco de Paula y la gran Duquesa de Luca. Para excluir a éstas de la sucesión, fue menester expedir un decreto particular antes que se publicase la Constitución, que se verificó al día siguiente. Por este decreto se declararon estas personas inhábiles para la sucesión por las circunstancias particulares que en ellas concurrían. Estas circunstancias han cesado. Y como en el art. 181 de la Constitución se concede a las Cortes la facultad de excluir de la sucesión a aquellas personas que no consideren capaces para suceder, y las Cortes dieron aquel decreto de exclusión, para que las cosas vuelvan a su orden, debe haber otro decreto que las restituya a él; y este decreto debe tener el carácter de ley, que determine la sucesión según prescribe la ley constitucional. La primera ley de esta naturaleza fue confirmada en las Cortes de Alcalá, y hasta entonces no tuvo fuerza de ley. La
} 
con carácter de ley», había otros que opinaban exactamente lo contrario, pero, curiosamente, invocando los mismos preceptos constitucionales. El precitado art. 181 de la Constitución comienza señalando que «Las Cortes deberán excluir de la sucesión...». Pues bien, cuando en el texto de la Constitución aparecen expresiones como «las Cortes deberán», «las Cortes determinarán», «las Cortes aprobarán», etc. ha de entenderse que en tales casos se adoptará la forma de «decreto de Cortes sin carácter de ley», que significa que son las Cortes, por símismas, sin intervención del Rey, las que decidirán. Y si relacionamos el art. 181 con el apartado tercero, del art. 131 de la Constitución, que se refiere a las facultades exclusivas de las Cortes, observamos que en el citado apartado se expresa que corresponde a las Cortes «resolver cualquier duda, de hecho o de derecho, que ocurra en orden a la sucesión de la Corona». Por tanto, en el asunto que comentamos, la categoría normativa revestirá la forma de «decreto de Cortes sin carácter de ley», esquivándose así, que el Rey pudiere intervenir.

Siguiendo este mismo argumento expresa el diputado Sr. Victorica, que cuando se trata de decretos relativos a la sucesión a la Corona, estos deben considerarse como una explicación de las leyes fundamentales y tal explicación pertenece a las Cortes, no necesitándose la sanción ${ }^{25}$. Partidario también de calificar este hecho como «decreto de Cortes sin carácter de ley», fue el diputado Sr. Muñoz Torrero, pero con algún matiz diferencial respecto al Sr. Victorica. Aquel diputado hizo especial hincapié en señalar que, efectivamente, no era una ley, sino un decreto declarativo en virtud de las facultades que la Constitución señala a las Cortes, pero no un decreto declarativo de la ley fundamental, sino de un hecho particular. Con este matiz el Sr. Muñoz Torrero pretendía evitar que se «pudiera dar margen a que los malévolos dijeran que a pretexto de aclaraciones tratábamos de alterar la Constitución ${ }^{26}$.

segunda, en tiempo de Felipe V, se obtuvo con consentimiento de las Cortes en 1713, y la tercera ley de sucesión es la que tenemos en la Constitución. Con que en orden a estas personas excluídas, que están comprendidas en la línea llamada por la Constitución, el decreto que se de para rehabilitarlas debe tener el carácter de ley, porque restablece el orden señalado en la Constitución y no hace más que remover el obstáculo que opuso un decreto particular a ciertas personas llamadas a suceder por la Constitución.» Vid. Diario de Sesiones de las Cortes, Tomo I, núm 9, 13 de Julio de 1820, pág. 74.

${ }_{25}$ "El Sr. Victorica: Un artículo de la Constitución concede a las Cortes la facultad de excluir de la sucesión de la Corona a aquellas personás que por sus circunstancias lo mereciesen. Las Cortes generales y extraordinarias, usando de esta facultad, juzgaron conveniente excluir en aquellas circunstancias al Sermo. Sr. Infante D. Francisco de Paula y a S. M. la Duquesa de Luca. Teniendo ahora las Cortes para derogar este decreto, parece que para esta derogación conviene seguir el orden que siguieron las Cortes extraordinarias en su establecimiento; es decir, promulgar un decreto, en que convendrá se observen las circunstancias que se requieren para la formación de las leyes, menos la sanción Real. Cuando se trata de decretos relativos a la sucesión a la Corona, estos debe considerarse como una explicación de las leyes fundamentales, y esta explicación pertenece a las Cortes, las cuales en virtud de esta facultad expidieron aquel decreto. Por consiguiente, perteneciendo a las Cortes exclusivamente la facultad de aclarar las leyes fundamentales, y siendo la presente una declaración de ellas no se necesitan en este caso la sanción Real.» Vid. idem.

26"E1 Sr. Muñoz Torrero: Voy a hablar de otra cosa, y es sobre una equivocación que se ha cometido en el Diario de Cortes días pasados, cuando se dijo que no era una ley, sino un decreto declaratorio en 
b') Diferencias fundamentales entre «decretos de Cortes con carácter de le» $y$ «decretos de Cortes sin carácter de ley»: por razón de la sanción y por razón de la materia.

Llegados a este momento, no apreciamos datos que nos indiquen con claridad las diferencias que pudieren existir entre «decretos de Cortes con carácter de ley » $\mathrm{y}$ «decretos de Cortes sin carárter de ley»; las dos características que se pretendían estimar como propias de los «decretos de Cortes con carácter de ley» (disposición general y perpetua y expresión de la voluntad del pueblo manifestada por sus representantes) han sido certeramente criticadas, desmontándose la estructura argumental sobre la que se sostenían, considerándose que las razones en que se fundaban eran asumibles plenamente por los «decretos de Cortes sin carácter de ley».

\section{a") Diferencia basada en la sanción.}

Indagando la respuesta al interrogante que con tanta precisión formuló el Secretario Sr. López, nos encontramos que la nota diferencial más importante entre «decreto de Cortes con carácter de ley» $\mathrm{y}$ «decreto de Cortes sin carácter de ley» es la sanción. Esto es, que los «decretos de Cortes con carácter de ley» (art. 108 Reglamento de las Cortes, de 1813) habrán de ser sancionados por S. M., mientras que los «decretos de Cortes sin carácter de ley» no precisarán la sanción Real.

La diferencia es transcendental, porque en el primer caso, al intervenir el Rey necesariamente, éste puede otorgar o negar la sanción, y si opta por esta segunda decisión se produce un bloqueo del «decreto de Cortes con carácter de ley» en cuestión durante cierto tiempo, según dispone la Constitución (art. 144-152 Constitución de 1812); sin embargo, en el segundo caso, cuando estemos ante «decretos de Cortes sin carácter de ley», el Rey no ha de intervenir porque la sanción no se exige para estos casos. Por tanto, la diferencia más radical entre ambas categorías normativas está en la exigencia o no del requisito de sanción.

\section{b') Diferencia basada en razones materiales.}

Pero si bien esta divergencia es incuestionable, no por ello ha de marginarse la otra nota diferencial de carácter sustancial que se fundamenta en razones materiales, en virtud de la cual revestirán la forma de «decreto de Cortes sin carácter de ley»

\footnotetext{
virtud de las facultades que la Constitución señala a las Cortes: no dije ni propuse jamás, ni fue la intención de las Cortes que este fuese un decreto declaratorio de la ley fundamental. Lo que yo dije fue que no era una ley civil, sino un decreto declaratorio y nada más. Es necesario que al extender el Diario se ponga el mayor cuidado en ciertas materias. Algunos Sres. Diputados manifestaron en efecto que esto era aclarar la ley fundamental; pero lo que yo dije fue que este era un decreto declaratorio de un hecho particular. Hago esta observación para que se corrija en el mismo Diario; porque el decir que se aclaraba la ley fundamental pudiera dar margen a que los malévolos dijesen que a pretexto de aclaraciones tratábamos de alterar la Constitución.» Vid. Diario de Sesiones de las Cortes, Tomo I, núm 13, 17 de Julio de 1820, pág. 174.
} 
todas las facultades de las Cortes contenidas en el art. 131 de la Constitución de 1812 , a excepción de la del apartado primero.

En este sentido merece señalarse con especial énfasis el contenido de la discusión que se produjo en la sesión del día 3 de Julio de 1811, en la Comisión de la Constitución, en torno al tema que directamente nos afecta. Y así, en el Acta correspondiente a la fecha señalada se manifestaba que la sanción del Rey se limitaba «a sólo las leyes», no necesitándose aquélla «en todas las otras determinaciones de las Cortes que sólo tuviesen carácter de decreto y que versaren sobre asuntos que, sin ser precisamente de legislación, les están atribuídos en las facultades que ya están señaladas» ${ }^{27}$. Un ejemplo ilustrativo, y que responde a los parámetros referidos, lo encontramos en la discusión acerca de la reducción a la mitad del valor de los portes del envío del Diaro de Cortes. En la polémica suscitada acerca de este particular se configuraron dos posturas contradictorias. Por una parte, se situaban aquellos diputados (Sres. Conde de Toreno, Cañedo, Golfín) que con el Sr. Gareli al frente consideraban que el asunto objeto de debate había de revestir naturaleza de ley y cumplir, en consecuencia, todos los trámites prescritos en la Constitución y en el Reglamento para tales casos. Y, por otra parte, se ubicaba el sector discrepante (Sres. Quintana, Villanueva y Cortés) que, ateniéndose fielmente a la Constitución y al Reglamento, y para evitar las «dudas» que frecuentemente se suscitaban para calificar un determinado dictamen como ley o como decreto de Cortes, «dijo -el Sr. Cortés-que en la misma Constitución estaban terminantemente clasificados y distinguidos los casos», de lo que «dedujo no ser una ley la que se proponía, sino un acto de gobierno de los que la Constitución atribuye a las Cortes, por estar comprendido en la facultad décimatercia de las mismas, que dice: 'establecer anualmente las contribuciones e impuestos'. $\gg^{28}$.

${ }^{27}$ Vid. Suárez, Federico, Actas de la Comisión de Constitución (1811-1813), Madrid, 1976, pág. 129.

28"La Comisión del Diario de Cortes, deseando que a los españoles de fuera de Madrid que quisiesen suscribirse a este periódico se les facilitase con la posible economía, proponía a las Cortes que en valor de los portes se rebajase la mitad de lo que pagaban los impresos que se remitían por el correo con fajas.

Esta propuesta dio margen a alguna discusión, habiéndose opuesto el Sr. Gareli a que se aprobase desde luego, pues considerando la providencia que promovía como una ley, opinaba que debían seguirse todos los trámites prescritos por la Constitución y el Reglamento del gobierno interior de Cortes para la formación y derogación de las leyes. Del mismo dictamen fueron los señores Conde de Toreno, Cañedo y Golfín, quien normalizó una indicación concebida en estos términos: 'Siendo en mi opinión una verdadera ley la resolución de las Cortes sobre disminución de precio de portes de los Diarios de Cortes, pido que el Congreso delibere si necesita o no la sanción Real.' Los Sres. Quintana y Villanueva fueron de sentir contrario, como también el Sr. Cortés, el cual, para evitar las dudas que frecuentemente se suscitaban con respecto a calificar un dictamen o una propuesta, y decidir si eran objeto de una ley o de un simple decreto obligatorio, dijo que en la misma Constitución estaban terminantemente clasificados y distinguidos los casos, pues todo lo que estaba comprendido en los límites de las facultades del Rey por sí solo o del Poder ejecutivo no podía ser ley, como tampoco podía serlo todo lo que estaba encerrado en las facultades de las Cortes, puesto que ni éstas por sí solas ni el Rey podían hacer una ley, sino que debía hacerse por la cooperación de las dos potestades; $y$ aplicando este principio a la decisión presente, dedujo no ser una ley la que se proponía, sino un acto de gobierno de los que la Constitución atribuye a las Cortes, por estar comprendido en la facultad decimatercia de las mismas, que dice: 'establecer anualmente las contribuciones e impuestos.' Declarado el punto suficientemente discutido quedó aprobada la propuesta 
En relación con la expresión «acto de gobierno», Gallego Anabitarte acusaba a Jellinek de incurrir en un error — cuando se refería a la Constitución de Cádiz ${ }^{29}$ , porque dividía los asuntos del poder legislativo en «legislación material» y provisión de «actos administrativos». Para Gallego Anabitarte era inadecuada la utilización de la expresión «actos administrativos», porque los asuntos enumerados a partir del apartado $2^{\circ}$ al $26^{\circ}$, del art. 131 de la Constitución de 1812 eran todo menos «actos administrativos», eran todo menos leyes formales, «eran decretos de Cortes emitidos expresamente sin sanción de ley», eran una «manifestación del ejercicio de una facultad con rasgos soberanos ${ }^{30}$. Sin embargo, la intervención del diputado $\mathrm{Sr}$. Cortés, a la que anteriormente nos hemos referido, parece desmentir en parte la rotunda afirmación de Gallego Anabitarte al atribuir el calificativo de 'acto de gobierno' a las facultades del art. 131, 2o al $26^{\circ}$ de la Constitución de Cádiz.

Carl Schmitt, con la inteligencia y agudeza que le caracterizan, distingue, como ya hemos afirmado, entre concepto de ley propio del Estado de Derecho y el concepto político de la ley. En el primer caso la ley es una norma jurídica, general y permanente; en el segundo caso, la ley es voluntad, mandato concreto, «un acto de soberanía»: «Les et quod populus jussit» ${ }^{31}$.

Así, pues, trasladando con enorme cautela ambos conceptos de ley elaborados por C. Schmitt a la Constitución de 1812 observaremos que, por una parte, están los «decretos de Cortes con carácter de ley», que se corresponden con el concepto de ley propio del Estado de Derecho, y por otra, los «decretos de Cortes sin carácter de ley», que se relacionan con el concepto político de ley, y que no son sino «actos plenamente soberanos» ${ }^{32}$.

De lo anteriormente señalado no puede resultar más explícita la voluntad del legislador de no confundir aquellas materias propias de «decreto de Cortes con carácter de ley», y en las que será precisa la sanción, de aquellas otras que,

de la Comisión del Diario, y se declaró no haber lugar a votar sobre la indicación del Sr. Golfín.» Vid. Diario de Sesiones de las Cortes, Tomo I, núm. 27, 31 de Julio de 1820, pág. 338.

${ }^{29}$ Vid. Jellinek, G., Gesetz und Verordnung, 1887, págs. 83 y 84, cit. por Gallego Anabitarte, Alfredo, op. cit., pág. 171.

${ }^{30}$ Vid. Gallego Anabitarte, Alfredo, op. cit., págs. 171, 172 y 178.

${ }^{31}$ Vid. Schmitt, Carl, op. cit., pág. 155.

${ }^{32}$ Que las materias que regulan los «decretos de Cortes» no tienen carácter de ley también se deriva del «concepto formal de ley» (Der sogennante formelle Gesetzes begriff) al que Carl Schmitt dispensa una atención especial. Para este autor, el concepto formal de ley se encontraría situado entre el concepto de ley propio del Estado de Derecho y el concepto político de ley.

Señala Schmitt, que el «concepto formal de ley» encuentra su origen histórico en la monarquía constitucional y en conexión con la lucha protagonizada por la representación popular que intentaba extender sus competencias sobre materias que no eran propiamente leyes, sino meros «actos políticos» como, por ejemplo, la aprobación del presupuesto, la declaración del estado de sitio, créditos extraordinarios, declaración de guerra, nombramientos, otorgamientos de gracia, concesiones de empresas, etc. Vid. op. cit., pág. 153. Materias todas ellas que se contienen en los apartados $2^{\circ}$ al $26^{\circ}$, del artículo 131 , de la Constitución de 1812 y que no se regulan por «decretos de Cortes con carácter de ley», sino por «decretos de Cortes sin carácter de ley». 
expresamente determinadas, corresponde a la voluntad soberana de las Cortes y en las que no es exigible la intervención del Rey mediante la sanción ${ }^{33}$.

El reconocimiento de estas dos categorías normativas viene a plasmarse en el texto definitivo de la Constitución y en los Reglamentos de las Cortes, pero, a pesar de los precedentes históricos más remotos y más próximos, hay diputados que no tienen aún las ideas suficientmente clarificadas sobre este particular.

\section{2) Etapa que comienza en 29 de Junio de 1821, fecha de aprobación del Reglamento de Cortes, y termina el 1 de Octubre de 1823.}

\section{A) Tensa relación entre las Cortes y el Poder ejecutivo y su repercusión en el concepto de ley.}

En la segunda etapa, que comienza en 29 de Junio de 1821, fecha de aprobación del Reglamento de las Cortes, y termina el 1 de Octubre de 1823, en que el Rey Fernando VII dicta un decreto en el que se declara la nulidad de todo lo aprobado por las Cortes durante los tres años anteriores, existe por parte de muchos diputados cierto recelo a la actitud del Rey. El monarca ya había demostrado en fechas no muy lejanas su predisposición al establecimiento del régimen absolutista, pero el Rey está al frente del Poder Ejecutivo y exige intervenir en la «potestad de hacer las leyes», en la parte que le corresponde, por medio de la sanción, según dispone el art. 15 de la Constitución de 1812.

En el marco de estas circunstancias, las relaciones entre el Poder Legislativo y el Poder Ejecutivo, cuya cabeza suprema la ostenta el Rey, manifiestan ciertos niveles de tensión, que, sin duda, repercutirán en la configuración del concepto de ley durante esta segunda y última etapa. Piénsese, que si anteriormente señalábamos que una de las diferencias entre «decreto de Cortes sin carácter de ley» $\mathrm{y}$ «decreto de Cortes sin carácter de ley» hallaba su fundamento en razones materiales —unas

\footnotetext{
${ }^{33}$ Ramón Salas, cuya obra Lecciones de Derecho Público Constitucional fue publicada, en su primera edición, en 1821, parece ignorar la Constitución, los Reglamentos de las Cortes de 1810, 1813 y 1821, y el contenido de los debates parlamentarios que incidieron fundamentalmente en la polémica planteada acerca del concepto de «decreto de Cortes con carácter de ley» y su diferencia con los «decretos de Cortes sin carácter de ley». Este autor clasifica el contenido del art. 131 de la Constitución del siguiente modo: en primer lugar, señala aquellas materias cuya regulación corresponde a «decreto de Cortes con carácter de ley» (así, art. 131, apartados 3o, $\left.7^{\circ}, 8^{\circ}, 10^{\circ}, 12^{\circ}, 13^{\circ}, 17^{\circ}, 19^{\circ}, 22^{\circ}, 24^{\circ}\right)$; en segundo lugar, hace mención a «actos de administración» (tomar caudales a préstamo en caso de necesidad sobre el crédito de la Nación - art. 131, 14- - constituye un "acto de administración» y, por consiguiente, comprendido en las atribuciones del poder ejecutivo; aprobar el repartimiento de las contribuciones entre los contribuyentes pertenece a la autoridad administrativa -art. 131, 15\%); y, en tercer lugar, ciertos actos que no perteneciendo exclusivamente a uno de los tres poderes se atribuye al poder legislativo por ser éste el más importante (tales son recibir el juramento al Rey, al príncipe de Asturias y a la Regencia —art. 131, 20; elegir Regencia o Regente del Reino - art. 131, 4; hacer el reconocimiento público del príncipe de Asturias - art. 131, 50 -; nombrar tutor al Rey menor - art. 131, $\left.6^{\circ}\right)$. Vid. Salas Ramón, Lecciones de Derecho Público Constitucional, Madrid, 1982, págs. 208 a 213.
} 
materias corresponderán regularse por «decreto de Cortes con carácter de ley» y otras por «decreto de Cortes sin carácter de ley»—, según se deriva del art. 131 de la Constitución de 1812, en esta segunda etapa se pretendió afianzar aún más dicho criterio con el fin último de evitar en lo posible situaciones conflictivas en las relaciones entre los dos poderes.

\section{B) Factor racionalizador tendente a clarificar las relaciones entre «decreto de Cortes con carácter de ley» y «decreto de Cortes sin carácter de ley»; artículo 110 del Reglamento de Cortes de 1821.}

Parece que los diputados que intervinieron en la elaboración del Reglamento de las Cortes, de 1821, eran conscientes de la situación caótica que se estaba produciendo en torno a la determinación de las materias que correspondía regularse por una $\mathrm{u}$ otra categoría normativa, y con tal objetivo introdujeron un elemento que contribuyó a clarificar las confusas ideas sobre el particular, aunque no llegó a eliminar totalmente las relaciones conflictuales entre las diferentes categorías normativas. Así, el diputado Sr. Romero expuso que la Comisión y la Secretaría habían dudado de si el decreto sobre el modo de ejercer los militares el derecho de ciudadano en las elecciones parroquiales, debía adoptar forma de «decreto de Cortes con carácter de ley» o de «decreto de Cortes sin carácter de ley», y después de una corta discusión se decidió que debía configurarse como «decreto de Cortes sin carácter de ley» ${ }^{34} ; \mathrm{y}$ otro casi en el que también puede observarse la actitud dubitativa para calificar una determinada norma lo hallamos cuando el diputado Sr. Becerra manifestó que el decreto sobre empleados que no hubiesen seguido al Gobierno debía ser «decreto de Cortes sin carácter de ley». (Lástima que no exponga los argumentos en defensa de su opinión) ${ }^{35}$.

Concretamente, el factor racionalizador tendente a clarificar las relaciones entre «decreto de Cortes con carácter de ley» $\mathrm{y}$ «decreto de Cortes sin carácter de ley» fue el art. 110 del precitado Reglamento, que dice así: «Todas las leyes o decretos dados por las Cortes deben pasar a la sanción de S. M., excepto las que pertenecen a las atribuciones de las mismas, según se expresa en el capítulo VII de la Constitución, art. 131, desde la segunda facultad hasta la vigésima séptima» ${ }^{36}$.

${ }^{34}$ "Leída y aprobada el acta de la anterior, se leyó una minuta de decreto sobre el modo de ejercer los militares el derecho de ciudadano en las elecciones parroquiales, presentado por la comisión de Corrección de estilo.

El Sr. Romero expuso que la comisión y la secretaría habían dudado si esta determinación debía correr como ley o como decreto, y después de una corta discusión se declaró que estaba conforme con lo acordado por las Cortes, y que debía correr como decreto.» (La discusión no fue lamentablemente recogida). Vid. Diario de Sesiones de las Cortes, celebradas en Sevilla y Cádiz, Gaceta Española, Cádiz, Lunes 30 de Junio de 1823, Sesión del día 29, pág. 275.

${ }^{35}$ Vid. Diario de Sesiones de las Cortes, celebradas en Sevilla y Cádiz, Gaceta Española, Cádiz, Martes 15 de Julio de 1823, Sesión del día 14, pág. 332.

${ }^{36}$ Aunque en verdad debiera decir vigésima sexta, porque veintiséis son los apartados que contiene el artículo 131 de la Constitución. 
Ciertamente, este precepto no constituye una absoluta novedad, porque el contenido de este artículo podía deducirse igualmente interpretando correctamente el art. 131 de la Constitución, como ya hemos tenido ocasión de señalar en líneas precedentes. Pero para evitar situaciones de inseguridad que pudieran plantear dudas se estimó oportuno un artículo rotundo en sus términos como el 110, aunque la razón última que se hallaba tras esta novedad fuese la de limitar las injerencias del Rey sobre la regulación de determinados contenidos. Concretamente, y por referirnos a un caso concreto, en toda la materia concerniente a la Hacienda y; en general, a las contribuciones, las facultades de las Cortes se hacen más extensas con el fin de lograr en estas materias mayor independencia del Poder Legislativo, constituyéndose así una garantía frente a eventuales invasiones de otros poderes, fundamentalmente, del Poder Ejecutivo, y del Rey como cabeza visible del mismo ${ }^{37}$.

En definitiva, se trataba de preservar un conjunto de materias (art. 131, 2-26 de la Constitución) de exclusiva competencia de las Cortes, de posibles expansiones injustificadas de las facultades del Poder Ejecutivo. Piénsese que entre estas materias objeto de «protección» se encuentran algunas tan importantes como, por ejemplo, resolver dudas en el orden de sucesión a la Corona (art. 131, $3^{\circ}$ de la Constitución); dar ordenanzas al Ejército, Armada y Milicia Nacional (art. 131, $11^{\circ}$ de la Constitución). establecimiento de contribuciones (art. 131, $13^{\circ}$ de la Constitución); proteger la libertad de imprenta (art. 131, 24ํ de la Constitución); etc. Por tanto, las Cortes, «aparte» de la potestad legislativa (art. 131, $1^{\circ}$ de la Constitución), ostentan las facultades relacionadas en los apdos. $2^{\circ}$ al $26^{\circ}$ del art. $131^{38}$.

De cualquier modo, aun a pesar de la clasificación que introdujo el art. 110 del Reglamento de las Cortes, de 1821, entre ciertos diputados se manifestaba un cierto temor al peligro de aumentar las facultades del Poder Ejecutivo en detrimento del Legislativo. Temor fundado en las declaraciones de algunos parlamentarios que estimaban que ciertos decretos de los que las Cortes aprueban en uso exclusivo de

37"El Sr. Martínez de la Rosa: Aquí solo se trata de dar un tanto por ciento a los cobradores, sin decir si los ha de nombrar el Gobierno o el Ayuntamiento respectivo; y por consiguiente, no se deben involucrar cuestiones extrañas. Supongamos que el cobrador sea una persona nombrada por el Ayuntamiento: es claro que entonces no se roza en nada este artículo con lo prevenido por la Constitución. Mas importa aclarar que el proyecto que es está discutiendo no es una verdadera ley; una prueba material y de hecho es que no se han seguido los trámites prevenidos en la Constitución para la formación de las leyes; en cuyo supuesto, mal pudiera decirse en la fórmula del decreto que se habían observado. Tampoconecesitan estas resoluciones la sanción de S. M.; y es evidente que según nuestro sistema constitucional, la facultad de hacer las leyes reside en las Cortes con el Rey, sin que pueda haber ninguna, propiamente dicha, que no requiera tan augusta sanción. Mas en la materia de que se trata, y en todolo concerniente alas contribuciones, las facultades de las Cortes son más extensas y exclusivas; en lo cual está muy de acuerdo nuestro sistema con los de todas las naciones libres, pues siempre se ha cuidado de asegurar en punto a contribuciones la mayor independencia de los cuerpos representativos. Esta es su mayor garantía; este el principal freno contra el abuso de poder; y creería comprometida la libertad pública, si se menguase la autoridad de las Cortes en materia de tan suma importancia.» Vid. Diario de Sesiones de las Cortes, Tomo III, núm 95, 2 de Junio de 1821, pág. 2020.

${ }^{38}$ Vid. en este mismo sentido Comellas, José Luis, «Las Cortes de Cádiz y la Constitución de 1812» en Revista de Estudios Políticos, núm 121, Noviembre-Diciembre, 1962, pág. 104. 
sus facultades, precisan sanción Real, en contra de los términos expresos del art. 110 del Reglamento de las Cortes, de 1821 («... deben pasar a la sanción de S. M., exceptolas que pertenecen a las atribuciones de lasmismas (Cortes)...». Este desprecio que algunos diputados manifiestan contra la Constitución y el Reglamento de las Cortes, de 1821, no hace sino ocultar el conflicto que subyacía entre las Cortes y la Corona. En una intervención del diputado Sr. Oliver ante las Cortes, dijo: «No aumentemos las facultades del Poder ejecutivo a costa de las que tiene el legislativo ${ }^{39}$; y aunque con fecha anterior a la de aprobación del Reglamento de las Cortes, de 1821, esta sensación de recelo entre ambos poderes ya se manifestaba, y valga como muestra las palabras del diputado Sr. Calatrava, cuando afirmaba que la distinción entre «decreto de Cortes sin carácter de ley» $\mathrm{y}$ «decreto de Cortes con carácter de ley» «autorizaría a las Cortes para atribuirse facultades que excederían sus límites, destruyéndose por este medio el equilibrio que establece la Constitución. $»^{40}$.

En resumen, durante las dos etapas en las que hemos dividido el análisis de las relaciones entre «decreto de Cortes con carácter de ley».y «decreto de Cortes sin carácter de ley» hay una constante que ha permanecido en ambas, y es, concretamente, la conciencia jurídica extendida entre los parlamentarios de distinguir las dos referidas categorías normativas procedentes de las Cortes, no considerándose, por tanto, al «decreto de Cortes con carácter de ley» como producto único y exclusivo del Poder Legislativo.

Si bien en el primer período de la primera etapa ya se plantea en el seno de las Cortes si una determinada norma ha de revestir la forma de «decreto de Cortes con carácter de ley» o de «decreto de Cortes sin carácter de ley», sin embargo el cautiverio del Rey impide que éste pueda ejercer todas sus atribuciones entre las que se encuentra la de sancionar, lo que significa que no fuera posible aprobar «decretos de Cortes con carácter de ley». Las Cortes disfrutan de una posición superior respecto a los demás poderes del Estado. De manera, que los «Decretos de Cortes sin carácter de ley» coinstituyen la expresión más auténtica de la soberanía nacional

\footnotetext{
${ }^{39} \mathrm{El}$ diputado Sr. Oliver manifestaba lo siguiente: «Otros señores han dicho que algunos decretos de los que las Cortes dan en uso de las facultades que les concede la Constitución, necesitan de la sanción Real; pero la opinión que se ha seguido en las legislaturas anteriores, y la que ha adoptado el Gobierno, no deja duda alguna en que no serían facultades de las Cortes si para usarlas necesitasen de sanción. Entonces se diría que se necesita para fijar las contribuciones, para dictar las ordenanzas militares, y para otras cosas de esta clase, que son atribución de las Cortes y jamás se han sancionado. Lo mismo ha sucedido con las decisiones temporales; y si no, véanse las medidas extraordinarias tomadas en la última legislatura, y se verá que se dictaron por un decreto de atribución de las Cortes. No aumentemos las facultades del Poder ejecutivo a costa de las que tiene el legislativo, y no olvidemos que habiendo estimado las Cortes necesarias estas medidas mientras duren las circunstancias presentes, cada momento que pase sin ponerlas en ejecución, se le usurpa a la patria el bien que debían producir.» Vid. Diario de Sesiones de las Cortes, Legislatura Extraordinaria, Tomo I, núm, 45, 16 de Noviembre de 182.2, pág. 638.

${ }^{40}$ Vid. Diario de Sesiones de las Cortes, Tomo II, núm. 38, 4 de Abril de 1821, pág. 880.
} 
representada en el Parlamento, por cuanto están exentos de un eventual veto suspensivo por parte de S. M. ${ }^{41}$.

En el segundo período de la primera etapa se produce un avance muy importante en torno a la definición del concepto de «decreto de Cortes con carácter de ley». Después de un extenso debate parlamentario, en el que se discute si una determinada norma es «decreto de Cortes con carácter de ley»o «decreto de Cortes sin carácter de ley», llegamos a la conclusión de que las dos notas características que diferencian una categoría normativa de otra son: una de naturaleza formal, esto es, el «decreto de Cortes con carácter de ley» será objeto de sanción, y los «decretos de Cortes sin carácter de ley» quedan eximidos del cumplimiento de tal requisito; y otra de naturaleza material, es decir, a los «decretos de Cortes sin carácter de ley» les corresponderá la regulación sobre aquellas materias a que se refiere el art. $131,2^{\circ}$ $26^{\circ}$ de la Constitución de 1812 , y a los «decretos de Cortes con carácter de ley»el resto de materias excluídas de estos apartados.

Y para concluir cabe señalar, que en la segunda etapa se produce un afianzamiento de los criterios arriba señalados con la aprobación del art. 110 del «Reglamento de las Cortes», de 19 de Junio d 1821, que responde a las relaciones, en cierto modo recelosas, entre el Poder Legislativo y el Poder Ejecutivo, aunque las controversias acerca de la determinación de la categoría normativa adecuada para regular una materia concreta aún se plantea avanzado ya el «trienio liberal».

\footnotetext{
${ }^{41}$ Vid. Gallego Anabitarte, Alfredo, op. cit., pág.. 201, se refiere a que si determinadas materias son reguladas por «decretos» y no por «ley» es porque aquellos eran «actos de soberanía».
} 